http://dx.doi.org/10.30681/23588403v14i0116

\title{
O ENSINO DE ANÁLISE LINGUÍSTICA COM O GÊNERO TIRA EM UM LIVRO DIDÁTICO DO $6^{\circ}$ ANO DO ENSINO FUNDAMENTAL ${ }^{1}$
}

\author{
Paulo Herculano Ribeiro SANTOS (UNIFAP) ${ }^{2}$ \\ Rosivaldo GOMES (UNIFAP) ${ }^{3}$
}

Data de recebimento: $26 / 03 / 2020$

Data de aceite: $17 / 06 / / 2020$

\begin{abstract}
Resumo: O artigo apresenta uma análise de atividades propostas no Livro Didático de Língua Portuguesa do sexto ano a partir do uso de tiras como mecanismo para as práticas de análise linguística e reflexão dos usos linguísticos. Para embasar nossos estudos abordamos as discussões sobre Análise Linguística a partir de Bezerra e Reinaldo (2013) e Mendonça (2006); os estudos sobre as teorias de Gênero de Bakhtin (2003[1952/53/1979]) e Bronckart (1999) e a explanação sobre o gênero tira com base em Ramos (2017). A metodologia consiste em abordagem qualitativa interpretativista (BORTONI-RICARDO, 2008), com técnica de análise documental que possibilitou analisar como as práticas de Análise Linguística de vertente epilinguística e metalinguística são aplicadas no livro didático. Nossos resultados mostraram que há divergências quanto às abordagens de Análise Linguística em relação às propostas de exercício voltadas para gramática e ainda convergências quanto ao uso reflexivo através das práticas de Análise Linguística na construção de conceitos. Concluímos que no livro analisado há propostas de reflexão linguística, mas é preciso avançar mais ainda quanto a abordagem.
\end{abstract}

Palavras-Chave: Análise Linguística. Tirinha. Livro didático.

Abstract: The paper presents an analysis of the activities proposed in the sixth year Portuguese Language Textbook from the use of comic strips as a mechanism for linguistic analysis practices and reflection of linguistic uses. To support our studies we approach the discussions about Linguistic Analysis by Bezerra and Reinaldo (2013) and Mendonça (2006). The Studies on Gender Theories by Bakhtin (1997) and Bronckart (1999). And the explanation of the genre by Tira de Ramos (2017). The methodology consists of a qualitative interpretative approach (BORTONI-RICARDO, 2008), also documentary analysis technique that made it possible to analyze how the practices of Linguistic Analysis of epilinguistic and metalinguistic aspects are applied in the textbook. Our results showed that there are divergences regarding Linguistic Analysis approaches in relation to grammar-oriented exercise proposals, as well as convergences regarding reflexive use through Linguistic Analysis practices in the construction

\footnotetext{
${ }^{1}$ Este trabalho configura-se como uma pesquisa desenvolvida no grupo de pesquisa Núcleo de Estudos e Pesquisas Interdisciplinares em Linguística Aplicada (NEPLA/UNIFAP-CNPQ).

${ }^{2}$ Graduado em Letras Português com Habilitação em Língua e Literatura Inglesa da Universidade Federal do Amapá - UNIFAP. Macapá-AP. BrasiL. lano.paulo@gmail.com

${ }^{3}$ Doutor em Linguística Aplicada pela UNICAMP e pós-doutor em Educação. Professor do Departamento de Letras e Artes da Universidade Federal do Amapá e do Programa de Pós-graduação em Letras/PPGLET/UNIFAP. Macapá-AP. Brasil. rosivaldounifap12@gmail.com
} 
of concepts. We conclude that in the analyzed book there are proposals for linguistic reflection, but it is necessary to advance even more in the approach.

Keywords: Linguistic Analysis. Comic strip. Textbook.

\section{Introdução}

As práticas de atividades que envolvem uma reflexão sobre o uso da língua são direcionadas pelos Parâmetros Curriculares Nacionais (PCN, 1998), em específico os que tangem o ensino de Língua Portuguesa (LP). Dentre essas práticas está a Análise Linguística (AL), que possui duas vertentes: a Epilinguística e a Metalinguística (BEZERRA; REINALDO, 2013); nos proporcionando uma visão funcional da língua.

Apesar das adequações que o conhecimento perpassa durante o processo de transposição didática, os saberes desenvolvidos no âmbito acadêmico no que se refere às atividades de AL, geralmente, não alcançam o ensino básico ou chegam de forma deturpada. Como consequência disso, ainda é possível encontrar nos LD um estudo majoritariamente pautado na gramática normativa. Isso implica também na didatização, no que compete ao LD, que deve procurar estabelecer a integração entre as competências linguísticas (leitura, escrita, análise linguísticas) tendo como suporte o texto.

Bezerra e Reinaldo (2013) afirmam que existe uma divisão entre as abordagens quanto ao estudo das unidades linguísticas. De um lado, temos a abordagens de leitura e escrita, tendo como base as perspectivas teóricas enunciativas, e, de outro, temos o estudo do componente linguístico sobre o viés da norma e/ou descrição estrutural, sem relacionar o plano textualenunciativo. Isso nos leva a questionar se há na prática um trabalho consolidado quanto ao ensino embasado no uso $\rightarrow$ reflexão $\rightarrow$ uso pautado na AL e como os LD de LP têm abordado as teorias da AL?

Inclinamos o foco da discussão neste artigo para a análise e a descrição de como se apresenta a $\mathrm{AL}$ em atividades de leitura de um $\mathrm{LD}$ de $6^{\circ}$ ano que utilizam o gênero discursivo tira. A escolha por essa temática justifica-se por conta da necessidade de se analisar a inserção dos conteúdos de conhecimentos linguístico-gramaticais nos anos finais do Ensino Fundamental no que diz respeito tanto às práticas de leitura quanto de escrita.

Dessa forma, nosso objetivo é verificar se as propostas didáticas, apresentadas na obra Português linguagens $6^{\circ}$ ano, de autoria de Magalhães e Cereja (2015), coadunam com a indicação teórica da AL vertente mais enunciativa/discursiva, conforme defendido no campo 
da Linguística Aplicada ${ }^{4}$ por alguns autores. Além disso, intentamos descrever e analisar a maneira como as Tiras são expostas no LD a partir das práticas de AL.

Para atender aos objetivos propostos este artigo organiza-se em cinco momentos. No primeiro momento, trataremos sobre a discussão a respeito de análise linguística, em seguida, no segundo momento, explanaremos sobre as teorias de gênero, tendo por base a discussões de Bakhtin (2003[1952/53/1979]) e Bronckart (1999) e sobre tira a partir de Ramos (2007). Posteriormente, em um terceiro momento, apresentaremos a metodologia que embasa a pesquisa e a análise da pesquisa. Por último, no quinto momento, as considerações finais.

\section{Os caminhos percorridos pela Análise Linguística}

No século XIX, o objetivo dos estudos linguísticos consistia, de acordo com Bezerra e Reinaldo (2013), na identificação das línguas, promovendo assim um estudo histórico comparativo. Suas unidades de estudo eram as palavras e seus componentes. Ainda no século $\mathrm{XX}$, temos o surgimento de várias perspectivas teóricas sobre o estudo da língua, como as correntes: Estruturalista, a Gerativista e ainda as subcorrentes: Psicolinguística e a Sociolinguística. Já no século XXI, os aspectos teóricos mencionados acima continuam e se especificam, segundo Bezerra e Reinaldo (2013, p. 20) “as unidades da língua em destaque são palavra, frase, texto e discurso, acrescidas de outros sistemas semióticos”. A pesquisa sobre discurso, o gênero e o texto tem sido associada à análise linguística, que toma como perspectivas: descrever e explicar ou interpretar aspectos da língua; assim como utilizar a descrição para fins didáticos.

Ainda nessa direção, as práticas de AL, de acordo com Mendonça (2006), partem de uma concepção de língua como ação interlocutiva situada, sujeita às interferências dos falantes e nesse sentido a AL configura-se como uma ferramenta para a leitura e para a produção de textos, dando suporte a esses eixos. A sua metodologia é reflexiva, parte da observação dos casos particulares para a conclusão das regras, ou seja, por meio da indução. Essas práticas possuem dois tipos de reflexão: a reflexão construída sobre os usos linguísticos, epilinguagem; e a reflexão sobre os conceitos e classificações dos fenômenos linguísticos, metalinguagem (REINALDO; BEZERRA, 2013).

\footnotetext{
${ }^{4}$ Tal visão pode ser depreendida dos trabalhos de Geraldi (1984), Mendonça (2006), Barbosa (2010); Reinaldo e Bezerra (2013).
} 
Em relação à metalinguagem, de acordo com Reinaldo e Bezerra (2013), os estudos partem de dois métodos: a descrição, que compete à caracterização e à classificação dos estudos sobre o sistema linguístico no decorrer da história, utilizando assim nomenclaturas que, ao estudar um fenômeno, designa-se a ele um nome concomitantemente a sua definição.A epilinguagem, por outro lado, de acordo com Barbosa (2010), trata da reflexão sobre a linguagem, orientada para a utilização de recursos linguísticos de um contexto comunicativo. Ela auxilia o desenvolvimento de competências, capacidades e habilidades para o uso da língua(gem) a partir de práticas de leitura, produção e a reescrita de textos, de forma que o aluno possa comparar e refletir sobre o uso de sua linguagem $m$ diversos âmbitos e práticas de letramentos, inclusive o escolar (MENDONÇA, 2006).

Assim, considerando tanto as atividades epilinguísticas quanto metalinguística, corroboramos com a visão de Gomes (2017) para quem um ensino de AL que considere essas dimensões, pode proporcionar o ensino-aprendizagem não só desse eixo/objeto, mas também relacioná-lo com outros e favorecer o desenvolvimento de outras capacidade e habilidades que podem, a partir das propriedades dos gêneros - não fixas, mas flexivas - relativas à forma composicional, estilo, contexto geral de produção e ao tema dos gêneros, proporcionar atividades concretas de uso da língua, como por exemplo, melhorar o texto de um aluno em uma prática de produção escrita, adequando-o ao gênero -, os alunos realizam a uma análise linguística que trabalha tanto sobre o eixo epilinguístico (que palavra é mais adequada ao gênero - seleção de vocabulário e efeitos de sentido) quanto sobre o eixo metalinguístico (nesse caso, em relação ao texto, por exemplo, apresentação de contra-argumentos em um artigo de opinião).

\section{A Análise Linguística em documentos oficiais e no LDP}

Os PCN norteiam que o ensino de língua portuguesa deva estar articulado nos eixos usoreflexão- uso, através dos conteúdos que devem partir de uma reflexão gramatical unida a práticas de leitura e a práticas de produção textualpois “é na prática de reflexão sobre a língua e a linguagem que pode se dar a construção de instrumentos que permitirão ao sujeito o desenvolvimento da competência discursiva para falar, escutar, ler e escrever nas diversas situações de interação" (BRASIL, 1998, p. 34).

Em decorrência a isso, para a Base Nacional Comum Curricular extenso o eixo AL/Semiótica envolve processos cognitivos de análise e avaliação durante a leitura, produção 
de texto, bem como as materialidades dos textos e seus efeitos de sentido na composição dos textos, determinadas pelos gêneros e situação de produção. Assim, o documento destaca que "O conhecimento metalinguístico e semiótico em jogo - conhecimento sobre os gêneros, as configurações textuais e os demais níveis de análise linguística e semiótica - deve poder ser revertido para situações significativas de uso e análise de uso" (BRASIL, 2018, p.80). Esse eixo compreende, portanto, o conhecimento sobre a língua quanto à norma-padrão e suas semioses; se desenvolve transversalmente aos dois eixos: leitura/escuta e produção oral, escrita e multissemiótica, envolvendo análise textual, gramatical, lexical, fonológica e das materialidades das outras semioses.

\section{Gênero do discurso em Bakhtin e em Bronckart: algumas definições}

A perspectiva de gênero concebida por Bakhtin (2003[1952/53/1979]) traz como premissa, debater os gêneros do discurso em práticas, esferas ou campos sociais de atuação e as finalidades enunciativo-discursiva-ideológicas desses. Compreende-se desta forma que a diversidade da atividade humana permite aos indivíduos proferir enunciados de diferentes naturezas envolvidos nos usos que fazemos da linguagem.

Bakhtin/ Volóchinov (1997[1929-30]), em Marxismo e Filosofia da Linguagem, trata da necessidade de uma abordagem marxista, discutindo concomitantemente todos os domínios das ciências humanas. Bakhtin (2003[1952/53/1979]) compreende que a língua é um fato social, a qual atende as necessidades da comunicação, e que a fala é indissociável das condições de comunicação e ligada as estruturas sociais. Relacionada a diversidade da atividade humana, nessas estruturas sociais temos a variedade de usos da língua, pois "a utilização da língua efetuase em forma de enunciados (orais e escritos), concretos e únicos" (BAKHTIN, (2003[1952/53/1979], p. 280). Ainda de acordo com o autor, o enunciado atende a demandas específicas e as finalidades de cada esfera da atividade humana com seu conteúdo temático, estilo e construção composicional.

Assim, os enunciados, relativamente estáveis, como proposto por Bakhtin, são o que chamamos de "Gêneros do Discurso", os quais são infinitos, pois a variedade de atividade humana é inesgotável. Nesse sentido, “cada esfera da atividade humana comporta um repertório de gêneros do discurso que vai diferenciando-se e ampliando-se à medida que a própria esfera se desenvolve e fica mais complexa” (BAKHTIN, 2003[1952/53/1979], p. 280). 
Em uma perspectiva de transposição didáticos dos conceitos de gênero, articulamos neste artigo a proposta teórica de Bakhtin as feitas por Bronckar (1999) a partir de suas proposições teóricas do Interaciocionismo Sociodiscursivo (ISD). Nessa perspectiva, o gênero de texto é compreendido como pré-construtos, ou seja, construtos que existem "antes de nossas ações n, necessárias para sua realização" (MACHADO, 2005, p. 250). Desse modo, ao estudar as práticas de linguagem, Bronckart (1999) nota que as produções verbais têm aspectos diversos por estarem associadas a situações de comunicação distintas, sendo que a essas realizações de produção verbal, chamamos de texto. De acordo com a interação comunicativa e os agentes atuantes, o texto pode possuir diferentes formas, as quais são denominadas pelo autor de gêneros de textos ou textuais.

\section{Gênero tira: definições e contexto}

Para entendermos a utilização do gênero tira no ensino é necessário, primeiramente, conhecer sua definição. Ramos (2017) apresenta uma definição partindo, inicialmente, do verbete apresentado pelo Dicionário Houaiss da língua portuguesa, o qual indica que a tira seria um fragmento, ou ainda um segmento de histórias em quadrinhos, circulada no âmbito jornalístico. O que Ramos (2017) acrescenta em relação a essa definição é sobre modelo utilizado para a tira que "varia muito em razão do suporte e da mídia na qual ela for veiculada" (RAMOS, 2017, p.12). Outra característica que varia, de acordo com o autor, é quanto ao formato que ora se apresenta na vertical, ora se apresenta na horizontal, que é o mais tradicional.

Além disso, as tiras ainda podem ser duplas, o que as denomina de tiras de dois andares, isso quando estão no modo tradicional. É preciso compreender que esses modelos de tira nos mostram a necessidade de revisar o verbete tira mencionado anteriormente. Assim, entende-se que tira é como uma ação de linguagem (BRONCKART, 1999), isto é, um conjunto de operações de linguagens em um formato veiculado de histórias em quadrinhos impressas ou digitais que servem a um determinado ato comunicativo.

Dessa maneira, o gênero tira ou tirinha pode receber essa dupla nomenclatura, contudo Ramos (2017) salienta a importância e a cautela que temos que dar quanto a essas nomenclaturas para melhor compreensão do gênero. Para explicar o porquê disso, o autor ainda 
fala quanto à popularização do gênero no século XX, com a denominação tirinha, um dos motivos seria a circulação dos gêneros incialmente em jornais e depois na internet.

\section{Percurso metodológico-analítico}

A pesquisa realizada é de natureza qualitativa interpretativista (BORTONI-RICARDO, 2008), tendo como base a pesquisa documental. O livro analisado é o Português linguagens $6^{\circ}$ ano, de autoria de Magalhães e Cereja (2015), o qual selecionamos a partir dos seguintes critérios: o fato de ser correspondente aos anos finais do ensino fundamental e estar sendo utilizado e por ser uma das obras mais usadas no contexto das escolas públicas no contexto brasileiro conforme já atestado por diversas pesquisas. Para a organização do corpus realizamos um mapeamento das tiras presentes na obra que tinham relação com a construção de conceitos gramaticais e em exercícios voltados para a AL. Assim, foram mapeadas cinquenta e oito tiras e desse universo selecionamos apenas quatro, tendo visto a espaço limitado para discussão neste artigo.

Para a análise foram utilizadas como categorias: a) contextualização da tira: analisar se a tira está contextualizada com o tema proposto na unidade e capítulo; b) relação entre conteúdo e tira: observar se a tira apresenta um elo entre o conteúdo linguístico-gramatical proposto na unidade e no capítulo e c) relação entre tira e conceitos linguístico-gramaticais: observar como os conceitos gramaticais, na perspectiva da AL estão sendo explanados a partir do gênero Tira.

As quatro tiras, conforme já mencionado, são apenas uma amostragem do total presente na obra, sendo que duas estão presentes na construção de conceitos e as outras duas em exercícios voltados para abordagem dos conteúdos gramaticais. Feita a apresenta metodológica, passemos agora à análise dos dados. A análise mostrará como está sendo efetuado o trabalho com a AL por meio de exemplares de texto do gênero tira. Para isso, utilizamos uma amostra das atividades dispostas no livro didático que consiste em 4 unidades, como veremos no quadro 1 a seguir:

Quadro 1 - Organização do Livro Português Linguagens $6^{\circ}$ ano.

\begin{tabular}{|c|c|c|c|c|c|c|c|}
\hline & $\begin{array}{c}\text { Capítulo } \\
\mathbf{1}\end{array}$ & $\begin{array}{c}\text { Estudo do } \\
\text { texto }\end{array}$ & $\begin{array}{c}\text { Produção de } \\
\text { texto }\end{array}$ & $\begin{array}{c}\text { A língua em } \\
\text { foco }\end{array}$ & $\begin{array}{c}\text { De olho na } \\
\text { escrita }\end{array}$ & Divirta-se & - \\
\cline { 2 - 8 } $\begin{array}{c}\text { No mundo da } \\
\text { fantasia }\end{array}$ & $\begin{array}{c}\text { Capítulo } \\
\mathbf{2}\end{array}$ & $\begin{array}{c}\text { Estudo do } \\
\text { texto }\end{array}$ & $\begin{array}{c}\text { Produção de } \\
\text { texto }\end{array}$ & $\begin{array}{c}\text { A língua em } \\
\text { foco }\end{array}$ & Divirta-se & - & - \\
\cline { 2 - 8 } & $\begin{array}{c}\text { Capítulo } \\
\mathbf{3}\end{array}$ & $\begin{array}{c}\text { Produção } \\
\text { de texto }\end{array}$ & $\begin{array}{c}\text { Para escrever } \\
\text { com } \\
\text { expressividade }\end{array}$ & $\begin{array}{c}\text { A língua em } \\
\text { foco }\end{array}$ & Divirta-se & - & - \\
\hline
\end{tabular}




\section{Revista de Estudos Acadêmicos de Letras}

\begin{tabular}{|c|c|c|c|c|c|c|c|}
\hline \multirow{3}{*}{$\begin{array}{l}2^{\circ} \text { Unidade: } \\
\text { Crianças }\end{array}$} & $\begin{array}{c}\text { Capítulo } \\
1 \\
\end{array}$ & $\begin{array}{l}\text { Estudo do } \\
\text { texto }\end{array}$ & $\begin{array}{l}\text { Produção de } \\
\text { texto }\end{array}$ & $\begin{array}{l}\text { A língua em } \\
\text { foco }\end{array}$ & Divirta-se & - & - \\
\hline & $\begin{array}{c}\text { Capítulo } \\
2 \\
\end{array}$ & $\begin{array}{c}\text { Estudo do } \\
\text { texto }\end{array}$ & $\begin{array}{l}\text { Produção de } \\
\text { texto }\end{array}$ & $\begin{array}{l}\text { Para escrever } \\
\text { com adequação }\end{array}$ & $\begin{array}{c}\text { A língua em } \\
\text { foco }\end{array}$ & $\begin{array}{c}\text { De olho } \\
\text { na escrita }\end{array}$ & $\begin{array}{c}\text { Divirta- } \\
\text { se }\end{array}$ \\
\hline & $\begin{array}{c}\text { Capítulo } \\
\mathbf{3}\end{array}$ & $\begin{array}{c}\text { Produção } \\
\text { de texto }\end{array}$ & $\begin{array}{l}\text { A língua em } \\
\text { foco }\end{array}$ & $\begin{array}{l}\text { De olho na } \\
\text { escrita }\end{array}$ & Divirta-se & - & - \\
\hline \multirow{3}{*}{$\begin{array}{l}3^{\circ} \text { Unidade: } \\
\text { Descobrindo } \\
\text { quem sou eu }\end{array}$} & $\begin{array}{c}\text { Capítulo } \\
1\end{array}$ & $\begin{array}{l}\text { Estudo do } \\
\text { texto }\end{array}$ & $\begin{array}{l}\text { Produção de } \\
\text { texto }\end{array}$ & $\begin{array}{l}\text { A língua em } \\
\text { foco }\end{array}$ & Divirta-se & - & - \\
\hline & $\begin{array}{c}\text { Capítulo } \\
2\end{array}$ & $\begin{array}{l}\text { Estudo do } \\
\text { texto }\end{array}$ & $\begin{array}{l}\text { Produção de } \\
\text { texto }\end{array}$ & $\begin{array}{l}\text { Para escrever } \\
\text { com } \\
\text { expressividade }\end{array}$ & $\begin{array}{l}\text { A língua em } \\
\text { foco }\end{array}$ & $\begin{array}{l}\text { De olho } \\
\text { na escrita }\end{array}$ & $\begin{array}{l}\text { Divirta- } \\
\text { se }\end{array}$ \\
\hline & $\begin{array}{c}\text { Capítulo } \\
\mathbf{3} \\
\end{array}$ & $\begin{array}{c}\text { Produção } \\
\text { de texto }\end{array}$ & $\begin{array}{c}\text { A língua em } \\
\text { foco }\end{array}$ & $\begin{array}{c}\text { De olho na } \\
\text { escrita }\end{array}$ & Divirta-se & - & - \\
\hline \multirow{3}{*}{$\begin{array}{c}4^{\circ} \text { Unidade: } \\
\text { Verde, adoro } \\
\text { ver-te }\end{array}$} & $\begin{array}{c}\text { Capítulo } \\
1 \\
\end{array}$ & $\begin{array}{c}\text { Estudo do } \\
\text { texto }\end{array}$ & $\begin{array}{l}\text { Produção de } \\
\text { texto }\end{array}$ & $\begin{array}{l}\text { A língua em } \\
\text { foco }\end{array}$ & $\begin{array}{c}\text { De olho na } \\
\text { escrita }\end{array}$ & Divirta-se & - \\
\hline & $\begin{array}{c}\text { Capítulo } \\
2\end{array}$ & $\begin{array}{l}\text { Estudo do } \\
\text { texto }\end{array}$ & $\begin{array}{l}\text { Produção de } \\
\text { texto }\end{array}$ & $\begin{array}{c}\text { Para escrever } \\
\text { com coerência e } \\
\text { coesão } \\
\end{array}$ & $\begin{array}{l}\text { A língua em } \\
\text { foco }\end{array}$ & Divirta-se & - \\
\hline & $\begin{array}{c}\text { Capítulo } \\
3\end{array}$ & $\begin{array}{c}\text { Produção } \\
\text { de texto }\end{array}$ & $\begin{array}{l}\text { A língua em } \\
\text { foco }\end{array}$ & $\begin{array}{c}\text { De olho na } \\
\text { escrita }\end{array}$ & Divirta-se & - & - \\
\hline
\end{tabular}

Fonte: Elaborado pelo autor.

Para melhor compreensão dos dados, dividimos a análise em dois momentos que abarcam as categorias já apresentas: Tiras na construção do conceitos e Tiras como suporte em exercícios.

\subsection{Tiras na construção de conceito}

Considerando as categorias apresentadas, iniciamos pela seção "A língua em foco", capítulo dois, da $1^{\text {a }}$ unidade - página 39, na qual encontramos a tira de Fernando Gonsales. Nessa unidade, a tira está sendo utilizada para explanação e melhor compreensão do conteúdo “As Variedades Linguísticas”. Na Tira, uma mulher compra um papagaio que emite palavras pronunciadas na variedade "não padrão" da Língua Portuguesa e, ao chegar na loja onde o comprou, o atendente a recebe demonstrando o mesmo modo de fala do papagaio, conforme se pode observar na figura 1. Após a tira, são apresentadas três questões para serem respondidas. 
Figura 1 - Exercício do livro Português Linguagens $6^{\circ}$ ano

\section{A língua em foco}

AS VARIEDADES LINGUÍSTICAS

CONSTRUINDO O CONCEITO

Leia a tira abaixo, de Fernando Gonsales.

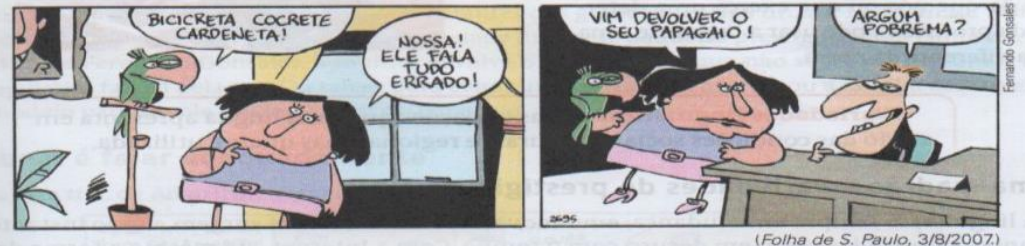

1. O humor da tira é construído a partir das diferenças de uso da língua portuguesa. No 1^ quadrinho. o papagaio fala algumas palavras que causam estranhamento à mulher.

a) Que palavras causam estranhamento à mulher? b) Como provavelmente ela diria essas palavras?

2. Para que o leitor compreenda bem a tira, é necessário que ele tenha conhecimento sobre como os papagaios aprendem a falar. De que forma isso acontece?

3. No $2^{\circ}$ quadrinho, a mulher procura o comerciante para devolver o papagaio a) Qual é a provável relação entre o homem e o papagaio?

b) A surpresa e a graça da tira estão na fala do comerciante. O que a fala dele revela?

Fonte: Cereja e Magalhães (2015).

O exemplo apresentado acima mostra que a tira está relacionada ao tema proposto no capítulo, que no caso, trata da linguagem e dos usos linguísticos. O conteúdo de ensino abordado é As Variedades Linguísticas e podemos observar que os questionamentos logo abaixo são reflexões dos diálogos apresentados na Tira, que nos levam a construir o conceito de variação linguística.

Conforme Mendonça (2006) a AL consiste em uma reflexão explícita e sistemática sobre o funcionamento da língua nas dimensões do texto, do discurso, da gramática com o objetivo de contribuir para o desenvolvimento das habilidades linguísticas e a análise dos fenômenos linguísticos. Essa abordagem é o que AL vem proporcionar: uma reflexão através do uso, comparando os usos da língua para construção do pensamento linguístico que nos leve ao conceito pretendido. Assim, podemos observar que a atividade que focaliza práticas de atividades epilinguísticas durante o processo de constituição do conceito e metalinguística na conclusão do conceito apresentado, logo após a atividade feita com Tira.

Avançando na análise, vemos a tira de Laerte, na figura 2, a seguir, está presente no primeiro capítulo da $4^{\mathrm{a}}$ unidade do LD, página 216. Nesse caso, notamos outra abordagem quanto aos conteúdos linguístico-gramaticais na construção do conceito, pois enquanto que na 
tira anterior há uma abordagem que elenca questionamentos que podem levar o aluno ao conceito, aqui, temos essa "reflexão" já vem pronta.

Figura 2 - Conteúdo do livro Português Linguagens $6^{\circ}$ ano

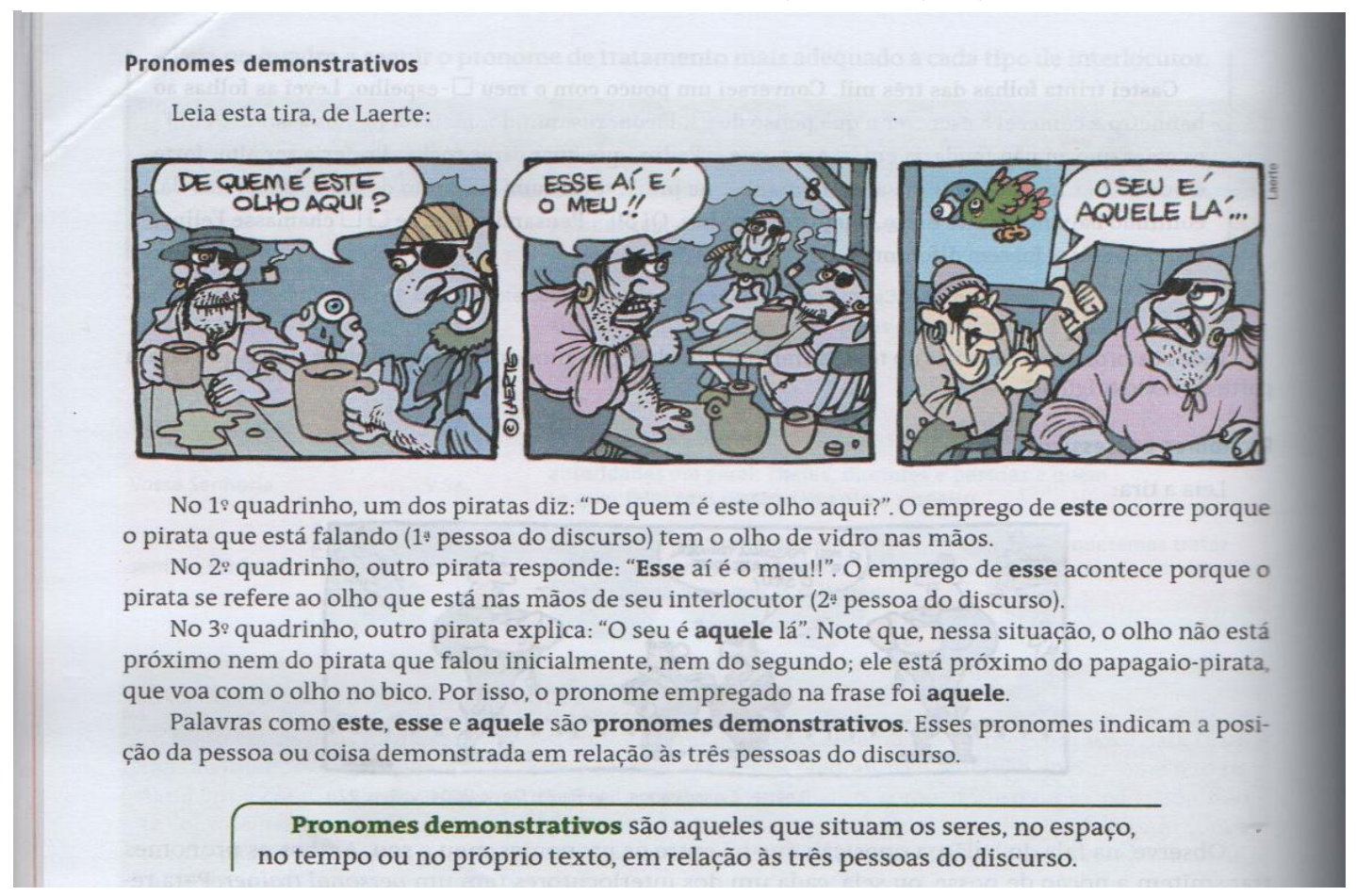

Fonte: Cereja e Magalhães (2015).

O conteúdo explanado é coerente com o tema Pronomes que norteia o capítulo, está relacionado ao conteúdo gramatical Pronomes demonstrativos e apresenta esses conceitos por meio das aplicações de elementos do próprio texto. Contudo, o que podemos notar é que não há um exercício epilinguístico, já que os elementos da tira são utilizados para uma finalidade metalinguística, sem muitas reflexões dos componentes linguísticos nem nível linguísticotextual nem enunciativo em relação ao gênero tira (BEZERRA; REINALDO, 2013). O emprego dos elementos está contextualizado, contudo não encontramos uma reflexão a respeito desses elementos que possa ser exercida pelo aluno. Assim, Bezerra e Reinaldo (2013) explicam que a atividade epilinguística que atua sobre a própria linguagem, ou seja, parti dos conhecimentos sobre a língua, criando hipóteses sobre a natureza da linguagem, compondo assim a atividade metalinguística. 


\subsection{Tiras como suporte em exercícios}

No exercício proposto na seção "De olho na escrita", do capítulo um, da $1^{\text {a }}$ unidade, página 30, temos a presença da Tirinha Menino Maluquinho, do cartunista Ziraldo. A primeira questão do exercício não consiste em levar o aluno a observar as informações do texto. Percebese, assim, que a atividade não é contextualizada para o aluno, lhe atribui as tarefas de contar quantas letras possuem a palavra "Maluquinho", em seguida, solicita a contagem dos fones, e por último identificar que pares de letras representam um único som.

\section{Figura 3 - Tira de Ziraldo}

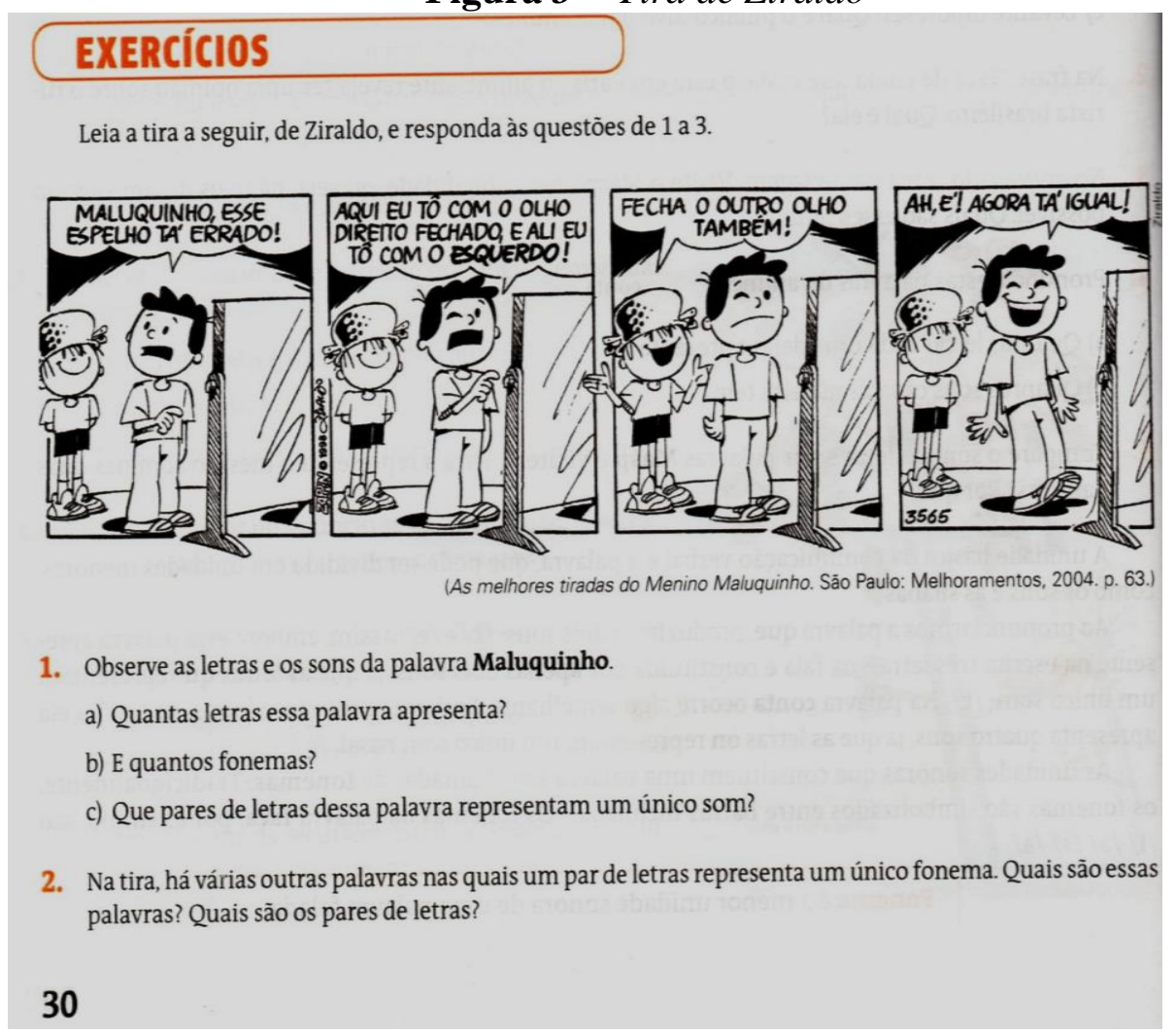

Fonte: Cereja e Magalhães (2015).

Devemos considerar nesse caso que as atividades relacionadas à fonética não exigem uma reflexão aprofundada, haja vista que os conteúdos são expositivos. Outro ponto a se considerar é a necessidade de haver um engajamento quanto ao meio de circulação do gênero. Essa postura, onde não se explora o aspecto reflexivo do aluno se opõe ao que é proposto pela AL, que de acordo com Reinaldo e Bezerra (2013) partir do gênero textual para alcançarmos às unidades linguísticas, argumentando que a língua está interagindo entre seus usuários. Promovendo ainda de acordo com as autoras a indução para uma análise a partir de atividades 
epilinguísticas, a observação dos dados e a sistematização da análise como consequência de atividades metalinguísticas.

Na questão seguinte o exercício solicita identificar quais palavras, e dessas palavras quais pares de letras possuem um único som. Observamos que não houve nenhum movimento voltado para reflexão do texto em relação ao conteúdo da tira, limitando a análise da língua a associação grafema/fonema. A questão três introduz uma abordagem quanto à variação linguística, entretanto sem fazer uma referência ao texto fonte, isolando a palavra "igual" do seu contexto linguístico.

Compreendemos que a utilização de gêneros textuais não pode se resumir a meramente um pretexto para atividades de cunho gramatical. Segundo Antunes (2007) os conhecimentos sobre as diversidades de gênero textuais são indispensáveis para termos uma competência comunicativa satisfatória, onde abordagens do gênero deve permear as atividades gramaticais, não desvinculando a gramática de texto, mas fazendo o aluno compreender o uso dela dentro do texto, significando sua atuação.

Figura 4- Exercício do livro Português Linguagens

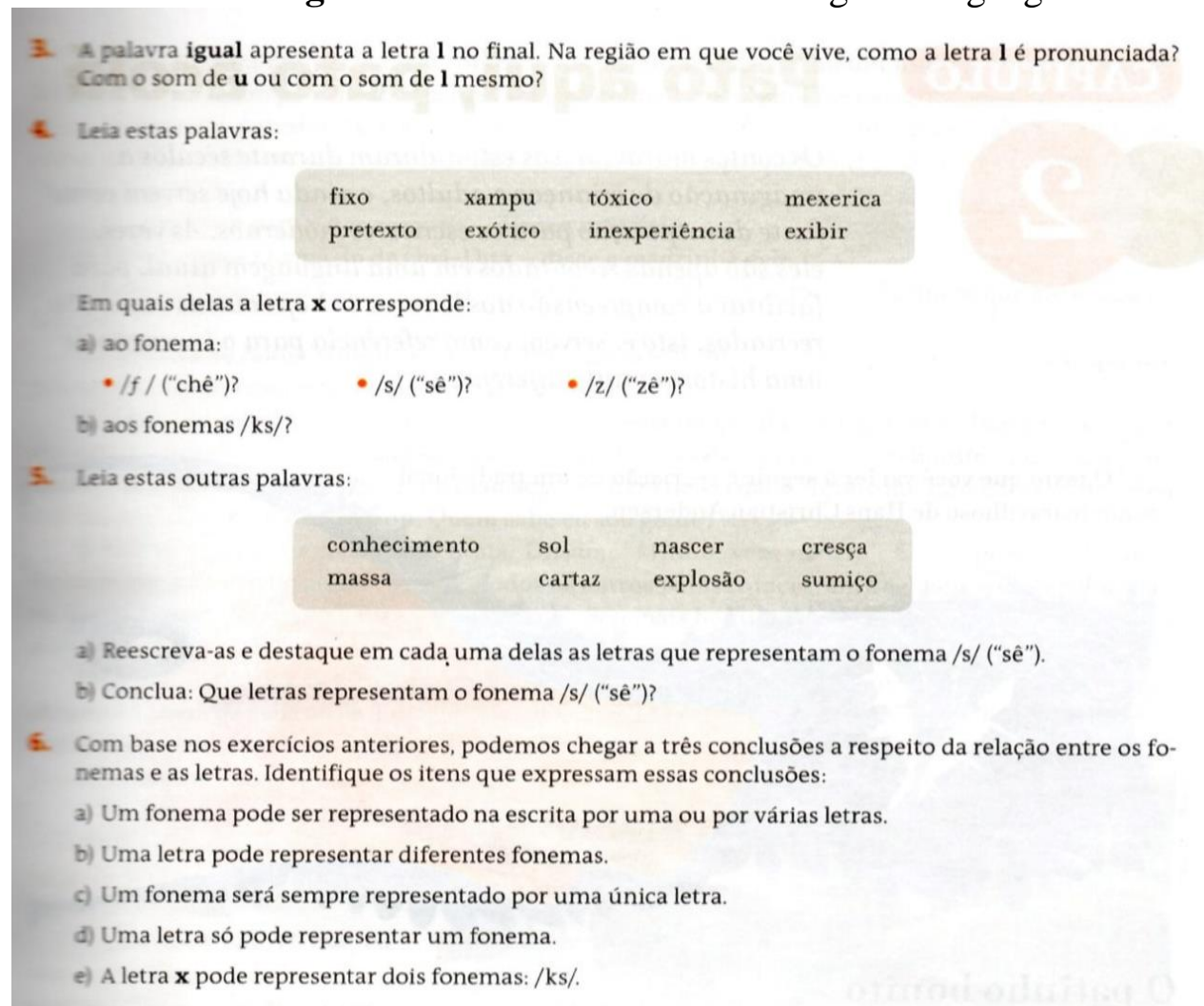

Fonte: Cereja e Magalhães (2015). 
As questões seguintes, localizadas na página 31 do LD, já se encontram focadas apenas no assunto abordado, Fonemas, conforme destaca-se as questões 4 e 5. Por fim, a última questão propõe selecionar as conclusões corretas sobre aquele exercício, dando ao aluno conclusões fechadas sobre a temática, não possibilitando a ele tecer suas próprias considerações. Além disso, a Tira utilizada no início do exercício não foi mencionada em nenhuma das questões trabalhadas, o que nos leva a concluir que o gênero, neste caso, torna-se apenas um recurso ilustrativo no LD, cujo uso resume-se apenas à estrutura linguística.

No primeiro capítulo da unidade três, página 149, temos como temática o Grau substantivo e o grau adjetivo, como exercício sobre o conteúdo Grau substantivo temos a Tira abaixo:

Figura 5 - Exercício do Livro Português Linguagens $6^{\circ}$ ano

\section{EXERCÍCIOS}

1. Leia esta tira, de Laerte:
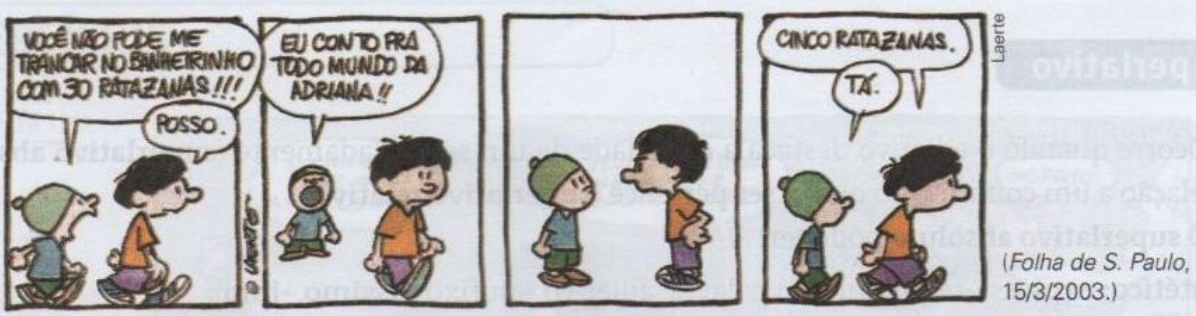

Há, na língua portuguesa, muitos substantivos que trazem sufixos formadores de aumentativo e diminutivo, mas perderam ao longo do tempo esses valores e adquiriram significados especiais.

a) Que palavra da tira exemplifica esse fenômeno?

b) Cite outros desses substantivos.

Fonte: Cereja e Magalhães (2015).

Aqui temos novamente apresentação de uma reflexão que poderia ser instigada ao aluno, desta forma não temos o exercício de uma atividade epilinguística de AL. Ao analisar a Tira e o que foi proposto na reflexão, notamos uma possível incoerência na compreensão e interpretação de ambas. A primeira pergunta feita na primeira questão é "Que palavra da tira exemplifica esse fenômeno?", os elementos da Tira: substantivos "banheirinho" e "ratazanas", que são substantivos e as repostas possíveis para essa pergunta não condizem com a reflexão, que se refere a sufixos de grau que podem ser empregados de outra maneira, pois no contexto da Tira, eles são empregados de forma não ambígua. 
A segunda pergunta, ainda dessa questão, já não faz mais referência a Tira, apenas ao fenômeno e reforça que não há uma relação concreta entre o conteúdo da Tira e o conteúdo gramatical explorado. E segundo Bezerra e Reinaldo (2013) o que deve ser feito é analisar a língua nas suas unidades mais amplas (Texto, gênero e discurso), e não de forma isolada. $\mathrm{Na}$ segunda questão, localizada na página 150 do LD, na imagem seguinte, a proposta é a adivinhação de quais substantivos fazem relação com os sufixos presentes. Não há uma reflexão sobre o uso do grau nesse exercício, a ferramenta é empregada, mas não se sabe o porquê do seu uso e nem de seu efeito em um contexto.

Figura 6 - Exercício do livro Português Linguagens $6^{\circ}$ ano

2. Leia estes substantivos:

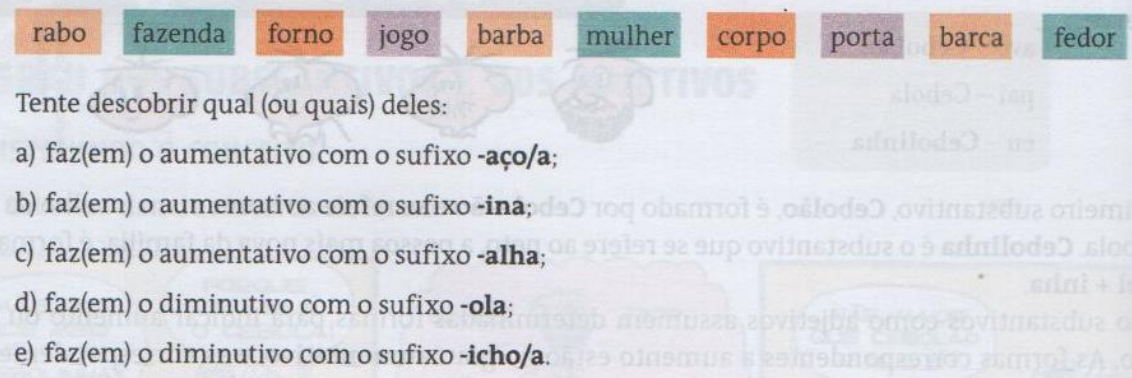

3. Entre as frases a seguir, há apenas uma em que os diminutivos não dão ideia de afetividade. Qual é ela a) Amorzinho, vem no colinho da mamãe, vem!

b) Não sei, maninha, como vou fazer para convencer nosso pai.

c) Ora, ora! Não chore! Você sempre será meu queridinho.

d) Não foi nada, filha! Deixe-me dar um beijinho no seu machucadinho, que ele sara já, já.

e) Que sujeitinho à toa! Não passa de um reporterzinho incompetente.

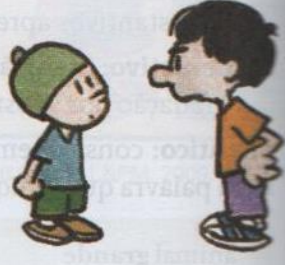

Fonte: Cereja e Magalhães (2015).

Já na terceira questão do mesmo exercício temos uma ligação com que foi citado no início do exercício. A pergunta trata sobre qual diminutivo não se refere ao sentido de afetividade dentre as sentenças apresentadas. Aqui sim temos uma atividade que permite uma comparação entre os usos, entretanto não encontramos na atividade elementos que remetessem a Tira apresentada, apesar de os personagens estarem postos logo ao lado da questão. O que temos aqui é o que Bezerra e Reinaldo (2013) apontam que o texto é apresentado como pretexto para estudar conteúdo previamente selecionado. Os conteúdos gramaticais não são usados para reflexão linguística em função do texto selecionado. 


\section{Considerações Finais}

Consideramos que o comportamento do LD Português Linguagens $6^{\circ}$ ano quanto às práticas de ensino de AL tem se mostrado convergente e também divergente. A análise dos dados, aqui apresentados, evidencia como a abordagem de AL atua no livro didático partindo desde uma estratégia reflexiva do uso até a constituição do conceito, tanto nas atividades propriamente ditas, quanto nos comandos que servem como explicações para a construção de conceitos. Foi possível analisar também que alguns exercícios voltados para o ensino de gramática ainda se detêm a métodos tradicionais, ou seja, voltados a uma gramática descontextualizada amorfa, fragmentada (ANTUNES, 2003).

Dessa maneira, os dados permitem observar que ainda após quase 30 anos de debates e discussões sobre o ensino de AL, que reiteramos - não vem substituir a gramática, mas trata de uma forma voltada ao uso - ainda encontramos exercício predominantemente voltados à gramática tradicional, como vimos na análise das tira usadas na construção do conceito e em exercício voltados ao estudos de conhecimentos linguístico-gramaticais, que ora atendem às bases teóricas, como dos PCN e da BNCC, ora ainda se pautam em uma abordagem de gramática tradicional, utilizando a tira como pretexto para explanação de conteúdos e aplicação de exercícios de nomenclaturas.

\section{Referências}

ANTUNES, I. Muito além da gramática: por um ensino de línguas sem pedras no caminho. São Paulo: Parábola, 2007.

ANTUNES, I. Aula de Português: encontro e interação. São Paulo: Parábola, 2003.

BAKHTIN, M. M. Estética da criação verbal. São Paulo: Martins Fontes, 2003[1979]. Trad. Paulo Bezerra. 4 ed.

BAKHTIN, M.M/VOLOCHÍNOV, V.N. Marxismo e filosofia da linguagem. Problemas fundamentais do método sociológico na ciência da linguagem. Trad. Michel Lahud e Yara Frateschi Vieira. 13 ed. São Paulo: Hucitec, 1997[1929-30].

BARBOSA, J. P. Análise e reflexão sobre a língua e as linguagens: ferramentas para os letramentos. In: ROJO, R. H. R.; RANGEL, E. O. (Org.). Coleção Explorando o Ensino: Língua Portuguesa. V 19. Brasília: Ministério da Educação, Secretaria de Educação Básica, 2010 . 
BORTONI-RICARDO, S. M. O professor pesquisador: introdução à pesquisa qualitativa. São Paulo: Parábola Editorial, 2008.

BRASIL. Ministério da Educação /Secretaria de Educação Básica. Base Nacional Comum Curricular: língua portuguesa. Brasília, 2018.

BRASIL. Ministério da Educação e do Desporto/Secretaria de Educação do Ensino Fundamental. Parâmetros Curriculares Nacionais: língua portuguesa, v2. Brasília, 1998.

BRONCKART, J. P. Atividade de linguagem, textos e discursos. Por um interacionismo sociodiscursivo. Trad. Anna Rachel Machado e Péricles Cunha, São Paulo, Educ, 1999.

BUNZEN, C.; ROJO, R.H.R. Livro didático de língua portuguesa como gênero do discurso: autoria e estilo. In.: COSTA VAL, M. G.; MARCUSCHI, B. (Orgs.) Livros didáticos de língua portuguesa: letramento e cidadania. Belo Horizonte: CEALE, Autêntica, 2005, p. 73117.

CEREJA, W. R.; MAGAlHÃES, T. C. Português Linguagens, 6. São Paulo: Saraiva, 2015. GERALDI, J. W. (Org.). O texto na sala de aula: leitura e produção. Cascavel: Assoeste, 1984. MENDONÇA, M. R. S. Análise linguística no ensino médio: um novo olhar, um outro objeto. In: MENDONÇA, M. R. S.; BUNZEN, C (Org.). Português no ensino médio e formação do professor. São Paulo: Parábola Editorial, 2006.

GOMES, R. ANÁlisE LINGUísticA E OBJETOS DIGITAIS DE APRENDIZAGEM. Revista Linguagem em Foco, v. 9, n. 1, p. 53-64, 18 ago. 2019. Disponível: $\quad$ https://revistas.uece.br/index.php/linguagememfoco/article/view/1534/1281. Acesso em: 05/12/2019.

RAMOS, P. Os quadrinhos em aulas de Língua Portuguesa. São Paulo: Contexto, 2018.

RAMOS, P. Tiras no ensino. São Paulo: Parábola Editorial, 2017.

REINALDO, M.A.; BEZERRA, M. A. Análise Linguística: afinal, a que se refere? São Paulo: Cortez, 2013. 